\title{
Developing the power of the pack: the long-term leadership impact of peer mentoring for female clinicians as part of the RCP's Emerging Women Leaders Programme
}

\author{
Author: Michael Walsh ${ }^{\mathrm{A}}$
}

With women making up $54 \%$ of junior doctors ${ }^{1}$ and almost $60 \%$ of new medical students ${ }^{2}$ why does it remain that only $32 \%$ consultants and $24 \%$ trust medical directors are women? ${ }^{1}$

Bismark et al explored reasons and remedies for the underrepresentation of women in medical leadership roles and identified three contributing drivers: capacity, capability and credibility. ${ }^{3}$ It has also been suggested that lack of effective mentoring for female clinicians aspiring to leadership positions has contributed to this under-representation at a senior leadership level. ${ }^{2}$

The RCP Emerging Women Leaders Programme launched in 2018 with an initial cohort of 12 female early career consultant physicians. It was designed to help address the underrepresentation of women in leadership roles within the medical profession by developing leadership skills and using peer and senior mentorship that centres around the drivers that Bismark described.

The RCP Emerging Women Leaders Programme uses facilitated peer mentoring known as 'Action Learning Sets'. ${ }^{4}$ There is increasing evidence to support the effectiveness of Action Learning Sets and female peer mentoring in healthcare settings. ${ }^{5}$

Our study focuses on the effect that facilitated peer mentoring has had on the women involved in the RCP Emerging Women Leaders programme. Participants had highlighted the significant impact of facilitated peer mentoring in their post-programme feedback and it was decided to build on this feedback to formally develop research within this field.

Participants are current and previous participants of the programme. Qualitative data is being gathered in two phases; a focus group and one-to-one interviews, which will be analysed using a hybrid method of emergent and a priori codes and themes.

Our intention is to share the results of the study and make recommendations for the use of facilitated peer mentoring to support under-represented groups in leadership roles within a healthcare setting.

\section{Conflicts of interest}

None declared.

\section{References}

1 The King's Fund. Women and medical leadership infographics. London: The King's Fund, 2014. www.kingsfund.org.uk/audio-video/ women-and-medical-leadership-infographics [Last accessed 13 November 2019].

2 Nath V, Marx C, Lees $\mathrm{P}$ et al. Improving women doctors' ability to achieve their full leadership potential. BMJ 2014:349:g7649.

3 Bismark M, Morris J, Thomas $L$ et al. Reasons and remedies for under-representation of women in medical leadership roles: a qualitative study from Australia. BMJ Open 2015;5:e009384.

4 NHS. NHS library and knowledge services. Skills for Success: the Health Library Staff Development Framework. NHS, 2007. www. libraryservices.nhs.uk/document_uploads/Staff_Development/ nlh_sdg_introducing_learning_sets_200808.pdf [Accessed 13 November 2019].

5 Varkey P, Jatoi A, Williams A et al. The positive impact of a facilitated peer mentoring program on academic skills of women faculty. BMC Med Educ 2012;12:14. 